\title{
West of Japan/East of Europe: Translating Architectural Legacies and the Case of Bruno Taut's Hyuga Villa
}

\author{
Paolo Scrivano $^{\mathrm{a*}}$ and Marco Capitanio ${ }^{\mathrm{b}}$ \\ a Department of Architecture, Xi'an Jiaotong-Liverpool University, Suzhou, China \\ $b$ Department of System Design and Engineering, Keio University, Yokohama, Japan \\ * Corresponding author: paolo.scrivano@xjtlu.edu.cn
}

\begin{abstract}
Based on communications presented at the international symposium 'West of Japan/East of Europe', hosted by the Department of Architecture at Xi'an Jiaotong-Liverpool University in concomitance with the exhibition 'Bruno Taut's Hyuga Villa in Atami, Japan', this text discusses the question of cultural translation in architecture departing from the example of Hyuga Villa, realised by Taut in 1936. Despite the inherently immobile status of architecture, architectural ideas travel widely, as well as their conceivers, the architects. The cultural passage implicit to translation is never flawless, though. Hyuga Villa offers a good case in point, since it was conceived by an architect who had only a partial grasp of local culture and who tried to integrate elements of both Western and Japanese design. But what are the implications of 'translating' architecture? Can we translate not only words but also images, details, building conventions, even aesthetic sensitivities? And is everything translatable? Applied to an artifact recognised today as an important testimony to the encounter between Western and Eastern design cultures, these questions relate to issues that are central to the debate on both architectural history and built heritage, proposing an alternative approach in terms of method and scope.
\end{abstract}

KEYWORDS cultural translation, Bruno Taut, Japan, Hyuga Villa, emigration, professional mobility, European architecture, Asian architecture, heritage

Received May 1, 2018; accepted May 22, 2018.

\section{Introduction ${ }^{1}$}

Despite the inherently immobile status of architecture, architectural ideas have always travelled widely, as well as their conceivers, the architects. The movement of knowledge related to architectural culture, however, has never been straightforward and without challenge. Concepts, notions, practical solutions, or building techniques need to be 'translated' to the use in new contexts, and this translation is problematic, since it is affected by multiple factors, on both the original and receiving ends. Issues associated with the implications, forms, and limits of translation are therefore central to the debate on architectural history and built heritage, offering an opportunity to explore alternative methodological approaches to the theme of conservation. The case of Hyuga Villa in Atami, Japan, authored by Bruno Taut-a German architect who had only a partial grasp of local culture and who tried to integrate elements of both Western and Japanese designprovides a precise illustration of these questions.

\section{Architecture as Cultural Translation}

In 1933, a few weeks after touching Japanese soil and at the request of a local publisher, Bruno Taut embarked on the preparation of a short manuscript containing his first impressions of the country where he had just arrived. Titled 'Japan seen with European eyes', this little volume appeared in 1934 in Japanese and only several years later in the language it had been written, German (Taut 2009). The fate of the publication is somewhat curious, since it had large circulation among Japanese readers much before reaching European audiences. But toward the end of the 1930s other two texts, Fundamentals of Japanese Architecture and Houses and People of Japan, made Taut's views on Japan's architecture available to a non-Japanese public (Taut 1936; Taut 1937). In many respects, these publications accounted for a 'translation' of Japanese architectural concepts into a foreign epistemological framework, in the same way as the Hyuga Villa, realised by Taut in 1936 in 


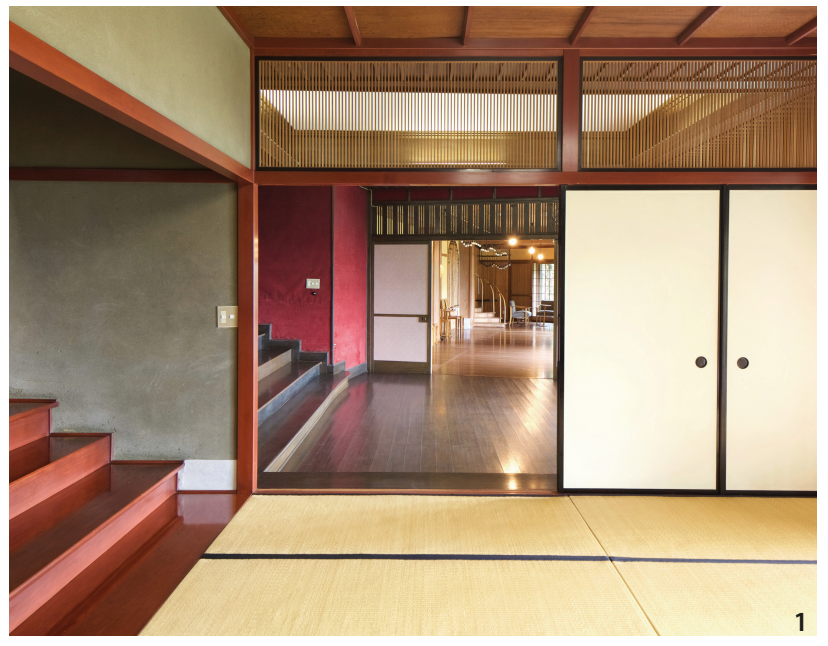

Figure 1 Hyuga Villa (Source: Dave Clough).

Atami, just before his departure for Turkey, provided an attempt to express elements of Western design into Japanese domesticity (Figure 1).

\section{Translating Architecture as Text}

The extent to which Taut's presence in Japan epitomised a process-bi-directional in scope-of cultural translation opens to the wider question of how architectural ideas, notions, and concepts move across geographies and nationalities. The expertise of architects, in fact, has always traveled, and not only as a consequence of professional mobility. Among the diverse modes of circulation of the knowledge related to architecture, one has certainly been the diffusion of publications that propagated information about building techniques, planning solutions, and aesthetic options to audiences comprised of both specialists and laymen. Books and treatises, of course, had begun to acquire a prominent status within Western design culture since the Renaissance. However, the novelty that characterised modern times was the expanded level of distribution of these materials, the consequence of an enlarged production of publishing artifacts and of a broadened demand and increased spending power among readers.

For example, a fundamental contribution to the growing diffusion of books and periodicals that occurred starting with the $18^{\text {th }}$ century consisted in the fact that they relied on visual apparatuses that crossed over language barriers and created a sort of lingua franca accepted across national boundaries. The best example comes from books such as those by Jean-Nicolas-Louis Durand, Auguste Choisy, or Julien Guadet, volumes that became a standard reference worldwide. All richly illustrated, these publications suggested a universalistic understanding of architecture, where general principles of construction or composition were proffered to a multinational and multilingual public of apprenticing architects. But if the dissemination of architectural culture found solid support in initiatives like those outlined so far, the worldwide circulation of books and other printed materials triggered problems of reception, first and foremost due to the translation of texts into different linguistic contexts. In the passage from one language to another, alterations of the original content and partial slippages of meanings occurred rather frequently, an aspect that raises questions about how 'common' was the ground over which the dialogues between architectural cultures took place.

French philosopher Pierre Bourdieu, for instance, has challenged the simplistic notion of intellectual life as 'spontaneously international', that is, as devoid of prejudices, stereotypes, and common places. International exchanges are inherently subject to 'structural factors' that generate misunderstandings, since knowledge circulates outside its context of origin and is reinterpreted in relation to the structure of its field of reception (Bourdieu 2002). Translation can be therefore intended as the action of translating a text from one language into another as much as the transfer and adaptation from different cultural settings of the notions or ideas that it contains ${ }^{2}$. Translation activity thus implies dealing with questions concerning the capacity of reception on the part of new audiences as well as the need to adapt the texts and concepts to new cultural environments.

The history of modern architecture provides plenty of examples of adaptive translation and transformative reception of specialised texts, of literary operations marked by a critical selection and a crucial mediation of original contents. The best known is probably the case of the English edition of Vers une architecture, Le Corbusier's first publishing success ${ }^{3}$. Released in French in 1923, Le Corbusier's book had several translations: the first was in German in 1926, followed one year later by one in English. The English translation was characterised by several inaccuracies, starting from the same title that became Towards a New Architecture, where the adjective 'new' emphasised the perceived novelty of modernism across the English Channel. The translator replaced Le Corbusier's preface with his own introduction, dropped some of the volume's key passages and in a number of occurrences adapted the narrative to his interpretation of the author's theory. As a result, successive generations of English readers had unknowingly access only to a considerably altered account of the positions of the Swiss-French architect. 
Another eminent example of how a book was heavily affected by its transposition in a new cultural setting is Aldo Rossi's L'Architettura della Città, a text whose various international translations appeared at a considerable distance of time from the original Italian and with significant shifts in meaning (Rossi 1966). Rossi's international translators faced several challenges in rendering his highly allusive and metaphorical language into different idioms. Numerous passages in the English edition bear witness to this. For instance, Rossi's recurrent use of the Italian expression 'fatto urbano' related to his view of the city as a stratification of social, cultural and morphological events, playing with the double meaning of the Italian word 'fatto', both 'fact', something that exists in reality, and the past participle of the verb 'fare', 'to make'; it also derived from the reworking of the French definition 'fait urbain', the evidence of Rossi's familiarity with authors like the urbanist Marcel Poëte and the sociologist Maurice Halbwachs. In the English version, 'fatto urbano' became 'urban artifact', an astute adaptation on the part of the translators but also one that rendered only in some measure the full meaning of the original expression.

In spite of actual linguistic challenges-the locution 'fatto urbano' was articulated in eight different ways in the text's 1973 German edition-it was not simply a question of words, though (Pellnitz 2014). Most of the terminology choices in L'Architettura della Cittä's American release were the result of a well-founded publishing strategy put into effect by the curators. As project editor Peter Eisenman wrote in the preface, the decision to avoid a literal translation in favor of a 'carefully revised' version derived from the assumption that the book could not be circulated among English-language readerships without a proper adaptation ${ }^{4}$. Still, the work made by the translators explains only in part the reasons of the volume's wide circulation in the United States. One is left wondering how a thematically dense and linguistically complex text such as Rossi's The Architecture of the City rose to the status of international reference. In other words, the translation of Rossi's book was successful not only because on the other side of the Atlantic it encountered a fertile ground for the reception of its theoretical content: the positive responses with which it was received were also due to a 'literary' format that suited the expectations of a small but influential circle of American academics and allowed for possible manipulations in its interpretation. In America Rossi was used to support a critical battle involving local actors, within which his book was presented as an 'analogical' byproduct of his work.

\section{Images, Details, Building Conventions}

The problems concerning the possible 'deviation' of messages in the passage from one context to another did not exclusively concern textual translations, however: they were also common to the cultural translation of visual material, that is, to their adaptation to settings characterised by different 'reading instruments' and by diverse social and ethnic sensibilities, as the case of the Chinese architect Liang Sicheng well demonstrates. Liang spent most of his early career focusing on the history of Chinese architecture (Fairbank 1994). At first, his studies remained predominantly textual, consisting in the analysis of historical records, literary sources, and building treatises. With time, though, Liang began to introduce photography and drawing as new methods of investigation, making an effort to transmit and translate building conventions of the past using a visual language recalling his educational background in America. Focusing on a local subject, traditional Chinese architecture, Liang therefore put into effect a cultural translation of notions as well as of tools of representation.

It is evident that mobility and emigration functioned as a catalyst for the translation of concepts applied to architecture. Social historians, for example, agree on seeing in migrants powerful examples of 'cultural brokers' (Shaw 2014). One can add that the presence of professionals or skilled laborers in foreign lands often prompted the rapid and effective translation and adaptation of specific disciplinary knowledge. For instance, well-established Western designers often received commissions outside Europe and North America that, among other things, helped improving local levels of expertise through a complex process of mediation often operated by local 'negotiators'. It is well known the case of Le Corbusier who, in 1950, was called upon by Indian authorities to design the new capital of the state of Punjab, Chandigarh. The presence of Le Corbusier and several other foreign professionals in India influenced more than one generation of South East Asian designers, insofar as foreign architects had to rely on locals to implement plans but also to circumvent occasional difficulties and resistances.

The example of Balkrishna Doshi is probably one of the most interesting. Doshi worked in the early 1950s in Le Corbusier's atelier in Paris (Bédarida 1987). Later, he probably acted as Le Corbusier's representative in the Indian city of Ahmedabad, where the French-Swiss architect received several commissions. When in 1955 he opened his own studio in the same city, Doshi's independent work departed from Le Corbusier's lesson to reach in the following 
years its own originality. Le Corbusier's legacy, though, remains evident in a number of projects begun during the second half of the 1950s, such as the loggia of the Institute of Indology, which recalls a similar solution in the convent of La Tourette. These analogies with works authored by the Swiss-French architect were probably due to Doshi's familiarity with techniques and solutions previously adopted in Le Corbusier's architecture and to the likely use in India of the same labor force, the same contractors, and the same suppliers of building material.

Albeit short, the presence of Le Corbusier in India gave the start to a fascinating process of formal imitation, characterised by the widespread duplication of many of the technical and aesthetic solutions adopted in the Chandigarh commission. Starting from the Punjabi city, with works like the University's Technical College, this phenomenon spread to the entire Indian Union. Probably the most paradigmatic example of propagation-and consequent simplification-of architectural models based on Le Corbusier's work can be found in the process of imitation that followed the realisation of the famous Unité d'Habitation in Marseilles. After the completion of the prototype, the proposal's essential ideas were picked up by others in different locations around the world.

The Unité gave the origin during the postwar years to a successful process of emulation, in particular in emerging countries. Part of a housing program initiated by the Banco Obrero, a sort of working-class mutual fund, Guillermo Bermúdez's Unidad de Habitación in Caracas referred with its own name to the Corbusian example, even though with a loss of the original communitarian intent (Fraser 2000, 113-124). In Shiv Nath Prasad's Akbar Hotel, in New Delhi, the original model of the Unité became the basis for a project where the initial concept of a housing unit containing services, was completely lost. In this hotel later turned into a governmental building, elements like the 'false' rue corridor bear testimony to a process of analogical appropriation of formal details within a totally different social agenda from the one set by the original model (Chatterjee 1985).

It is evident that the mechanisms of propagation of architectural models were in large measure accelerated by geographical, cultural or linguistic vicinity as well as by political and social opportunity, aspects that probably facilitated the process of translation of imported architectural notions. Between the 1950s and 1960s in the Portuguese-speaking countries of Africa, for instance, Brazilian architecture became a reference for the work of several architects, all trained in Portugal. The relatively less restrictive and more tolerant milieu of the colonies of Angola and Mozambique, in relation to the home country's political climate under the dictatorship of António Salazar, allowed for the implementation of a modernistic vocabulary whose employ was often barred on the European shores. In addition, the tropical environment induced Portuguese architects to look at the Brazilian examples, popularised internationally since the early 1940 s through various exhibitions and publications.

\section{Architectural Translation and Cultural Assimilation}

In addition to these aspects, the processes of translation of information related to architecture can also be considered from other perspectives, for instance by linking them to the creation of new frameworks of formal, visual or stylistic-and, in general, cultural-expectations. As Pierre Bourdieu illustrated in his La Distinction, there is a close correspondence between the production of taste and the formation of class structures (Bourdieu 1979). Taste and aesthetic opinion participate in a conflict over the control of the social space through an 'accumulation of cultural capital', whereas dominant social groups put into practice strategies of distinction by defining and trying to impose a 'legitimate' aesthetic sensitivity, or 'good taste'. The implications of Bourdieu's argument on this analysis of the phenomena of cultural translation in architecture are relevant.

During the $19^{\text {th }}$ century, for example, the mobility of large groups of individuals had an active role in initiating a process of universalisation of architectural values. In many countries interested by strong flows of migration, the presence of groups of immigrants impacted local construction activity, leading to the adoption of select building techniques and typologies and, ultimately, to the shaping of models of life and aesthetic preferences. These questions complexify the subject of the importation and reenactment of building traditions; and, in general, raise questions related to how design and architectural cultures are translated and adapted to new geographical contexts. Alongside a 'high' end approach, practiced by intellectual and professional elites, it existed more or less occasionally a 'low' end attitude, one where users and inhabitants rose to the rank of protagonists of the process of cultural assimilation of building types.

A similar understanding can perhaps be applied to the worldwide success of $19^{\text {th }}$ and $20^{\text {th }}$ century Eclecticism. If comparable plans and resembling decorations can be found in edifices located in places as diverse as France, Belgium, Turkey, Argentina, Brazil, but also China, it was 
due to the mobility of architects and artists, the cosmopolitanism of the clientele, the presence of artisans and skilled workers (often themselves immigrants), but also to the aesthetic appreciation of an increasingly transnational general public. In many ways, one common denominator of most of the processes so far described was a tendency to acquire and reuse specific knowledge, unfamiliar to a given context, in order to produce novel and distinctive results. This idea of taking and 're-assembling' a heterogeneous set of information was openly advocated during the $20^{\text {th }}$ century as a possible strategy for cultural assimilation. The cannibalism metaphorically evoked by Brazilian poet and playwright Oswald de Andrade, the founder in 1928 of the literary review Revista de Antropofagia, implied a 'digestion' of notions necessary to the creation of a national identity, as he wrote in his 1924 Manifesto da Poesia Pau Brasil (de Andrade 2000).

Indicating a line of action for his fellow Brazilian intellectuals, De Andrade propounded the incorporation of both indigenous and European civilizations, through the 'swallowing' of their cultural expressions. Starting with the 1930s, the concept of cultural anthropophagy would become a distinctive trait of Brazil's intellectual life, as it would be embraced by artists, men of letters, and also architects: in the world of architecture, in particular, it was used to provide ideological legitimacy for the emergence of a national modernist idiom.

The metaphor of cannibalism can be one way to illustrate an important facet of the medium of cultural translation in architecture: another one can be the concept of hybridity. In recent decades, the term hybridisation has surfaced in several disciplines to frame the discussion on cultural exchange and cultural blending. For example, the Argentinian anthropologist Néstor Canclini has addressed the subject by positing 'hybrid cultures' as the proper vehicle to by-pass the traditional separation between modernism and modernisation that dominates many Latin American countries (Canclini 1990). His discussion and those of others about hybridisation have then been transferred to architecture, with a proliferation of usages. No doubt, a multiplicity of terms and theories could be used to describe the processes of circulation and cultural translation of architectural knowledge. Carried around through travels, emigration, dissemination of images, and translation of words, architecture has become in modern times the vehicle for the transmission of cultural values, whether within small circles of experts and intellectuals or on a scale that affects large sections of the general public.

\section{Preliminary Conclusion: Heritage in Translation}

Taut's attempt at culturally translating Japan's architectural culture for Western audiences, through his publications, and Western design methods for his Japanese clients and acolytes, through the design of Hyuga Villa, reflected highly idealised perceptions of the 'other' on both sides. His 'European eyes' saw in Japanese architecture the concrete materialisation of aesthetic values-minimalism, pure geometry, simplicity of forms-that were shared by many modern architects in the Old Continent and that were allegedly exemplified by artifacts such as the ancient complex of Katsura Imperial Villa in Kyoto. Taut's Japanese admirers, on their part, found in his work a solid confirmation of their quest for modernisation, an aspect that made plain the anxieties generated by their country's rapid social and economic transformation. All in all, these translations of values manifested a process of bi-directional production of cultural expectations.

At a distance of many years, the account of Taut's encounter with Japan might appear of little interest for the contemporary debate on built environment's heritage. Yet it points at translation's growing role in today's world in establishing shared cultural values and historical narratives, since the definition of heritage resides on forms of cultural legitimation that are more and more determined at transnational level. The elaboration of new criteria of historical preservation, in fact, reflects a cultural demand that is oftentimes encouraged and nourished by international example, but also complex processes of conceptual translation and adaptation. The case of Hyuga Villa-of its origins, its material characteristics, and its implicit strategies of conservation-can therefore provide with new insights into a question of increasing relevance for the built heritage.

\section{Hyuga Villa: An Act of Architectural Translation $^{5}$}

Presenting an under-researched building by a $20^{\text {th }}$ century master to an international audience may be a good-enough reason to motivate architectural research. Nonetheless, Hyuga Villa by Bruno Taut interests us as a unique case of cross-cultural breeding between East and West: at the time of its completion, in fact, the building stood at odds with mainstream Modernism in Europe on the one hand, and with traditional Japanese architectural language on the other. In an age where cultural exchanges across countries can occur at digital light-speed, it is worth examining how a German architect interpreted and 


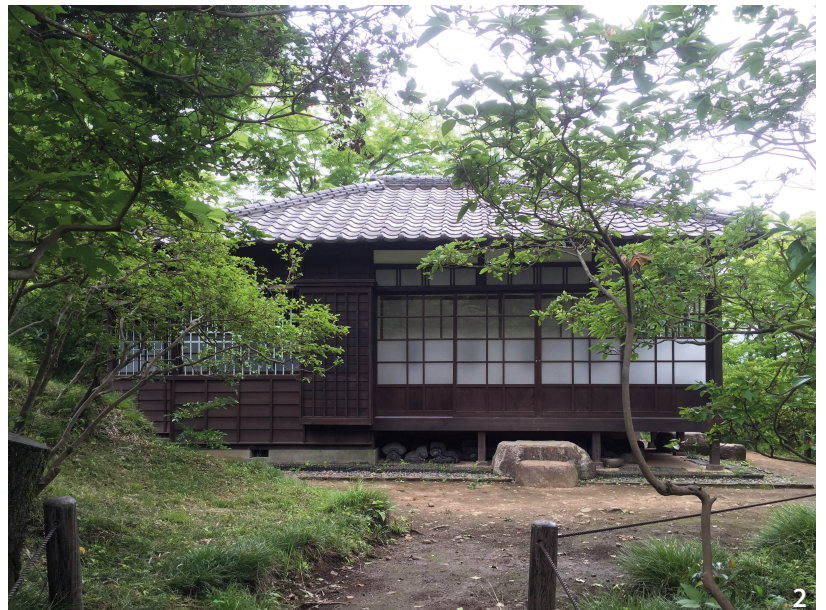

Figure 2 Taut's home—Senshintei-in Takasaki (Source: Marco Capitanio).

translated architectural elements of a foreign culture in the 1930s. As art historian Michael Sullivan put it, we have come to a point in ... the East-West confrontation where it is legitimate to ask ... what the significance of this interaction is for the future of art.' (Sullivan 1989, 271) Moreover, from the point of view of built heritage, this villa is a unique case where the fragility of materials and the novelty of detailing require a mix of Western and Eastern conservation attitudes: an emphasis on both physical integrity and immaterial authenticity (Ceccarelli 2017).

The refurbishment of Hyuga Villa (kyū hyūga bettei旧日向別邸) - in Atami City, Shizuoka Prefecturecompleted in 1936, is the only existing project that German architect Bruno Taut (Königsberg 1880; Istanbul 1938) realised during his two and a half-year stay in Japan $^{6}$. This building embodies a deeply personal reflection on Japanese architecture, mediated through Taut's European sensibility. As a hermeneutical tool to analyse the villa and to appreciate its current meaning as built heritage, this text will make use of the concept of 'translation', pragmatically defined as 'the act of changing something from one form to another'. Before delving into the building itself, though, a biographical and historical framework is required.

\section{Taut in Japan}

After spending 1932 in the Soviet Union and disappointed with his experience in the country, Bruno Taut returned briefly to Berlin where he had been working at various times since the beginning of the $20^{\text {th }}$ century. Having been blacklisted by the National Socialist Party because of his political and architectural inclinations, Taut decided to flee Germany together with his partner, Erica Wittich,via
Switzerland and France, boarding in Marseille a ship that would bring the couple to Italy, Greece, Turkey, and the Soviet Union. From Moscow they then crossed Siberia by train, to finally reach Vladivostok.

Taut officially accepted the invitation to go to Japan to deliver a series of lectures from architect Isaburo Ueno, who himself had lived in Berlin and Vienna and who would constantly act as Taut's own translator from Japanese. Ueno, together with other architects such as Gonkuro Kume, was in fact part of the Nippon International Architectural Association, which was strongly interested in bringing European architects to Asia to promote the virtual link between traditional Japanese and Western modern architecture. Taut had already been invited to Japan in 1930, but he had been forced to decline the invitation because of time constraints.

Taut and Erica arrived in Japan by ship on May 3, 1933. For the following day, the architect's 53rd birthday, Ueno had organised a visit to Katsura Imperial Villa in Kyoto, where Taut was struck by the modern and restrained character of the architecture. Taut lectured (from May to June 1933), wrote to earn some money (from July 1933), and traveled around Tokyo and Kyoto, also providing consultancy for the Kogei research institute in Sendai (from November 1933 to March 1934) and for the porcelain manufacturer Okura (in June 1934). In May 1934 he visited Katsura Villa for the second time.

On August 1, the couple moved to Takasaki, a small town some one hundred kilometers North-West of Tokyo, where Taut started to work as a designer of furniture and objects for Fusaichiro Inoue and for the Industrial Design Institute of Gunma Prefecture. The house were Taut and Erica lived-senshintei (洗心亭) - is part of the shorinzan (少林山) temple ground, but sits isolated from the main building and is still in very good condition, having survived to these days nearly unchanged (Figure 2).

Taut settled there thanks to Inoue, an active figure in the cultural milieu of Gunma Prefecture, a cultural patron who later established strong ties with Antonin Raymond, entrusting the latter with the design of his own house in Takasaki. Living in senshintei was a first-hand experience of the local way of life and of the Japanese traditional house; pleasures and hardships were extensively described in Taut's book Houses and People of Japan, published in English in 1937. Nippon mit europäischen Augen gesehen (Japan seen with European eyes) appeared in June 1934, while February 1935 saw the opening of MIRATISS, a shop in the Ginza neighborhood of Tokyo, selling Inoue's and Taut's artifacts. 

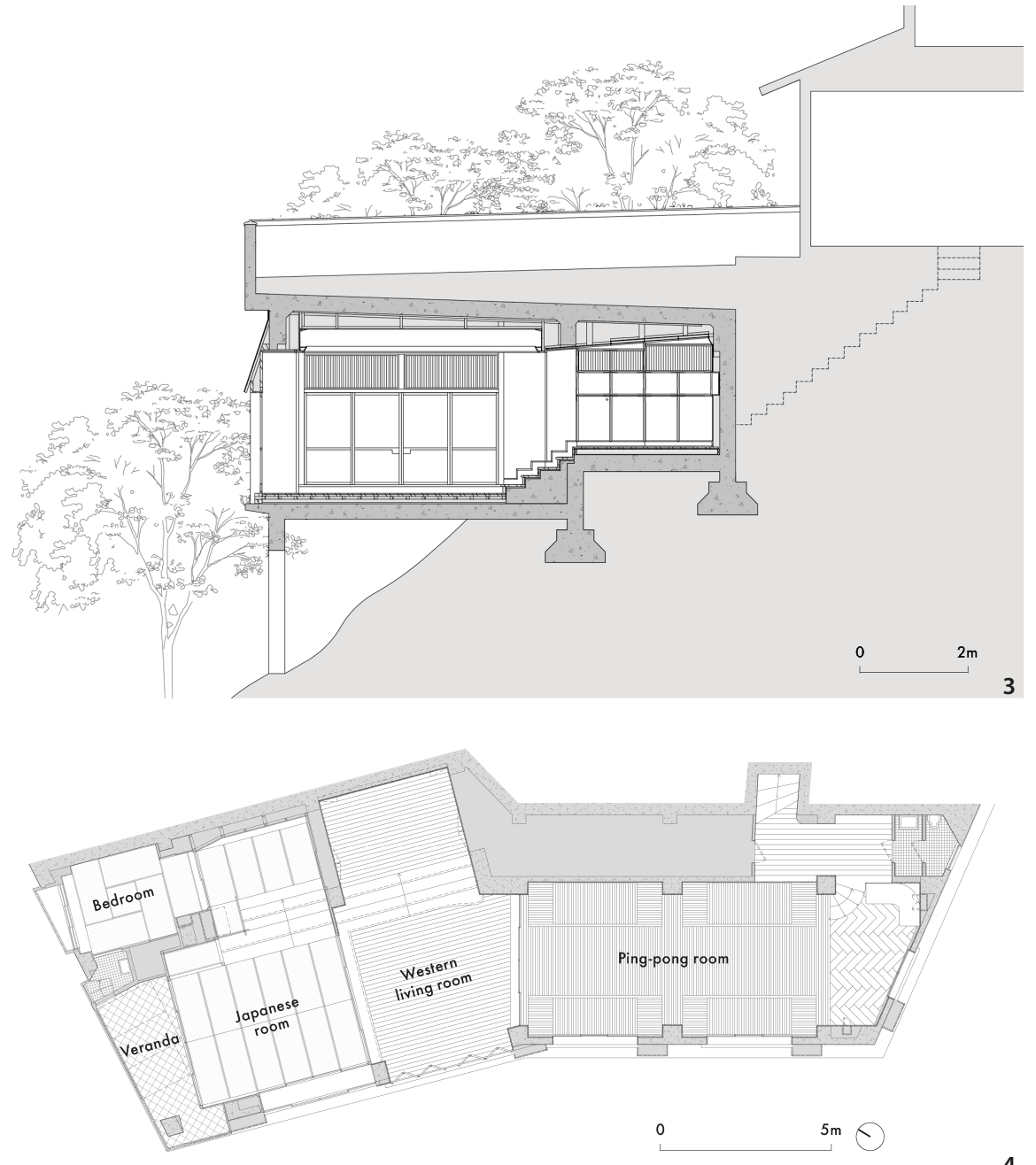

Figure 3 Cross-section of Hyuga Villa, showing the spatial relationship between the upper and lower structures (Source: Marco Capitanio).

\section{Hyuga Villa}

In April 1935 Taut was asked by businessman Rihei Hyuga to design the interiors of a concrete structure built under his house in Atami, on a steep cliff along the Pacific coast. Because of the sloping site, the concrete addition had the purpose of providing a flat surface for a garden in front of the upper building. Taut's task was thus to redesign the basement as a recreational space to be enjoyed especially during the hot summer months (Figure 3). Hyuga did not have a clear program, beside the desire to have Japanese- as well as Western-style rooms. Taut came up with the proposal of arranging the concrete basement into three distinct spaces: a ping-pong room, a Western-style dining room, and a Japanese room that included a bedroom and a veranda (Figure 4). Furniture and lamps were designed by Taut too. The design was prepared in four months and developed with the assistance of Tetsuro Yoshida's architectural office, while construction was completed in thirteen months.

Let us now examine in detail some of the features of
Hyuga Villa, seen through the lens of translation (refer to the visual summary in Figure 6). Steep stairs link the upper house with the underground basement. While descending, the visitor faces a see-through latticed screen (1a), made of strung bamboo poles, offering a view toward the ping-pong room and the South-facing windows. Proceeding into the first room, after a short, sweeping stair with a bamboo handrail (2a), one realises that bamboo has also been used as a wall covering at the North-eastern corner and as a supporting pole to which a series of hanging light bulbs are attached. These were novel ways to employ bamboo, attributable to Taut's foreign sensibility.

Taut had a special admiration for bamboo, one that can be traced back to his visits to Katsura Villa. In fact, as explained by means of text and photographs in Houses and People of Japan (Taut 1937, 27), he was particularly impressed by the bamboo fence surrounding Katsura's garden, where living bamboo plants are intertwined with the fence itself (2b). Stringing together bamboo poles, as Taut did for the latticed screen and handrail, appears to be 


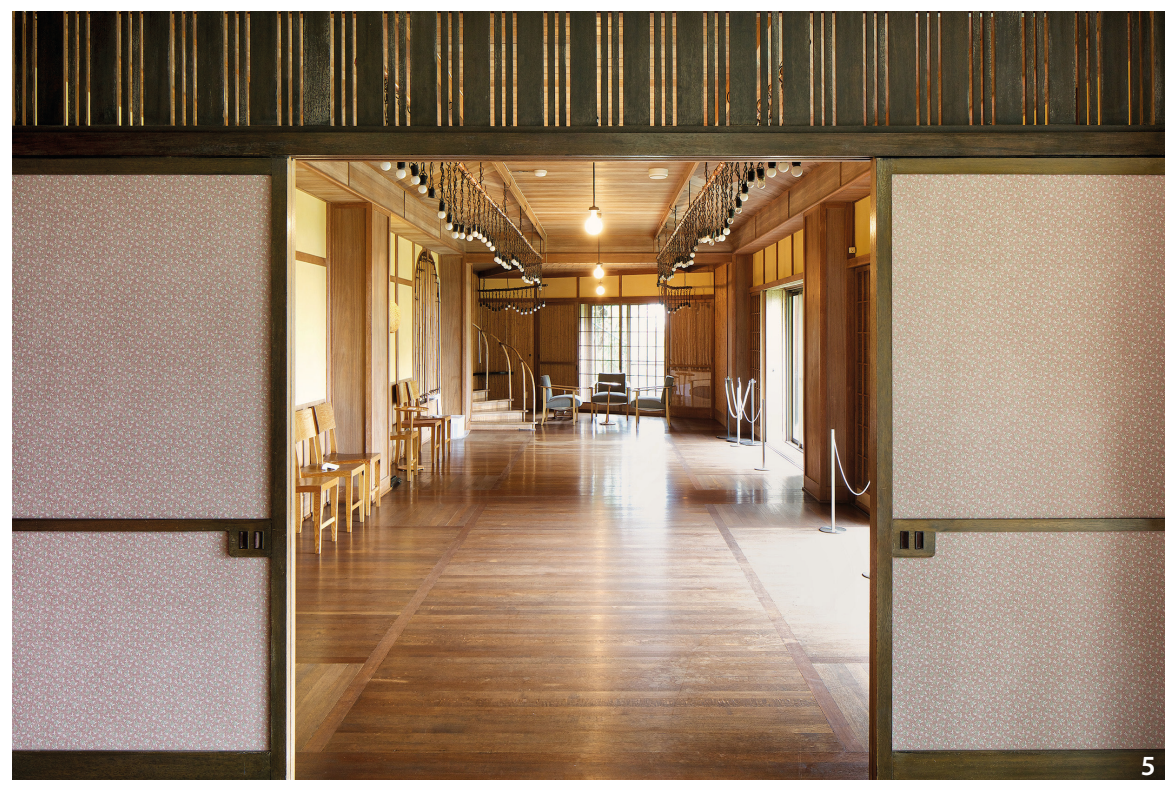

Figure 5 Ping-pong room as seen from the western-style living room (Source: Dave Clough).

a direct adoption of the technique seen in Katsura Villa, migrated from an exterior to an interior space. Along these lines, Taut documented the particular way in which the underside of Kyoto's villa is sometimes concealed by a series of bamboo poles (1b), forming a grate blocking access and view, but allowing the necessary airflow (Taut 1937, 282-283). In addition to adapting an outdoor architectural detailing to an indoor space, Taut asked the carpenters to seamlessly place fine bamboo twigs as a wall covering, a difficult and unusual task. A third case of translation in the ping-pong room is represented by the hanging light bulbs. They are arranged in wavy fashion (3a), joined to a bamboo pole by a reed chain made of bamboo links (tsuru). Just before his departure for Istanbul Taut sketched a watercolor ( $3 \mathrm{~b})$ where he described these light bulbs with the following comment: 'Wer da bauet an der Strasse, muss die Leute reden lassen' (He who builds along the street, should let people talk). While it might only be a speculation, the wavy alignment of hanging paper lanterns, to the right and left side of streets leading to a shrine during local festivals in Japan, reveals perhaps the visual source of Taut's design (Figure 5). In this solution Manfred Speidel sees instead a reference to a 1915 design for a wrought iron piece by Taut for the Berlin Secession (Speidel 1994, 279).

The Western living room is a short and deep space, created by the demolition of a preexisting concrete wall dividing the upper and lower levels. By joining these two spaces with a stair, the architect realised a raised platform with a dramatic view over the ocean, almost appearing as a water wall. To offer an unobstructed view, slidingfolding windows (4a) are employed, so that, when fully open, they practically disappear. One may argue that these particular windows are a reference to Japanese screens (4b), which open and fold in a comparable manner. The function of Japanese screen, though, is opposite to that of Taut's windows-screens conceal, while the sliding-folding windows of Hyuga Villa afford maximum view and serve as 'living byōbu'. On the North side of the elevated platform a conscious act of architectural translation is visible, what Taut called a 'modern tokonoma' (5a) (Taut 2003, 174). In fact, in traditional Japanese architecture, there is a predetermined niche in a house where to display hanging scrolls, flower arrangements and the like-the tokonoma (5b). Being much fascinated by this device, the architect believed that it would be possible to provide also contemporary Western dwellings with a reinterpretation of the tokonoma, to the benefit of the overall spatial quality. In the Western living room, thus, Taut designed a long recess for the display of small paintings, with a storage space to its left and right.

Dividing the Western living room from the Japanese living room are wood and cardboard doors-fusumasliding under a lintel surmounted by the so-called ranma (6a). Ranma here appears as a very simple latticed screen, made of thin vertical wooden sticks. While this looks like an inconspicuous design, ranma in residential architecture is usually a decorative element, for example featuring carvings of animals or plants. Taut closely looked at the ranma between the first and second room of the old shoin (study) of Katsura Villa, sketching it in his diary (6b) with the comment: 'Hier, wo das Volk Ornamente liebt, nur Stäbe, nur Raumabschluss' (Here, where the common people love ornaments, are only sticks, just a spatial division) (Taut 


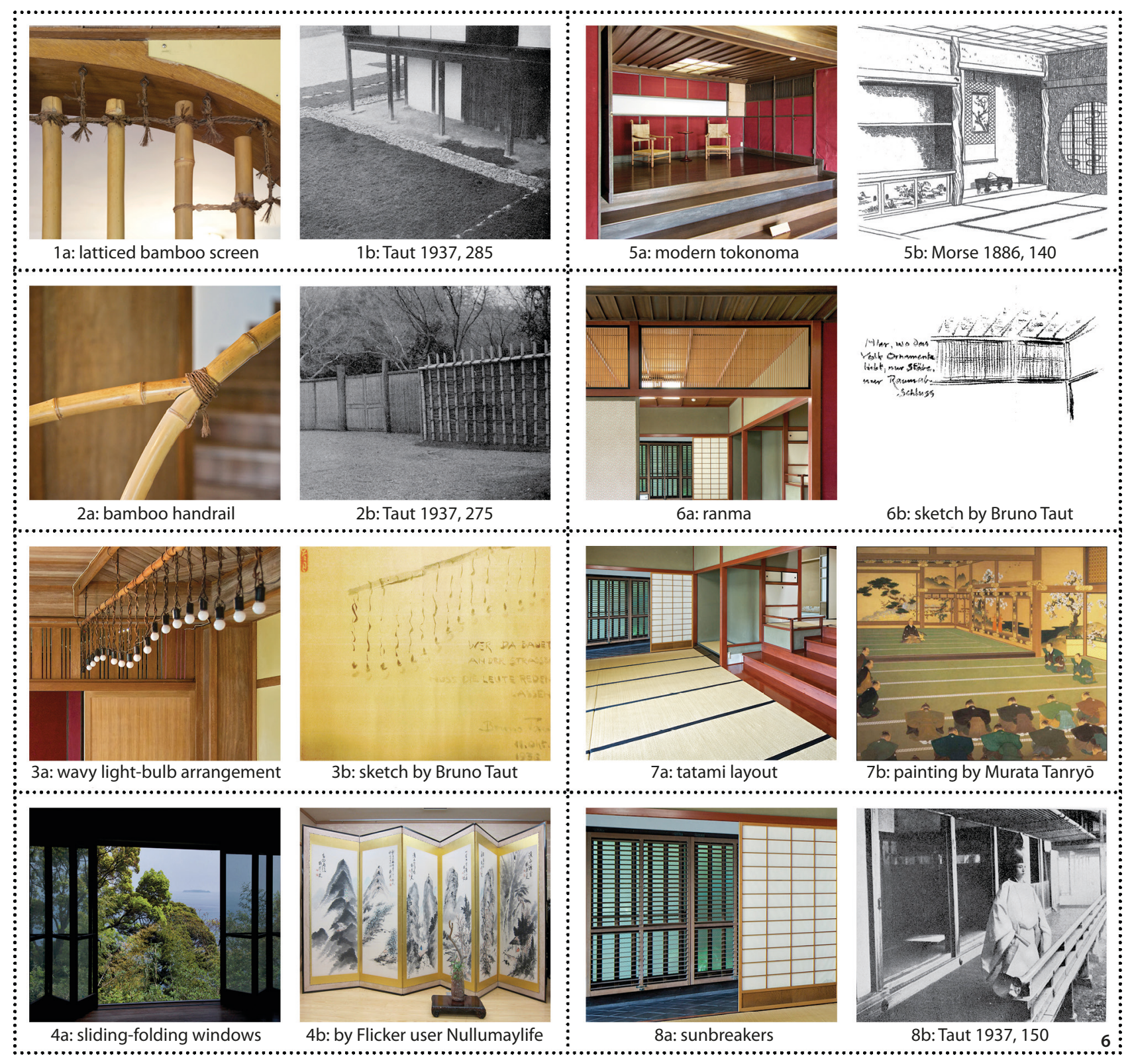

Figure 6 Graphical summary of Taut's acts of translation throughout the building (Source: photographs of Hyuga Villa by Dave Clough).

1937, 286). The design of the Japanese room is both the most traditional and the most modern, in the sense that the overall effect is restrained and simple. The layout of the tatami (straw mats, approximately $90 \times 45 \times 5.5 \mathrm{~cm})(7 \mathrm{a})$ is typical of large halls and temples-the so-called fushūgi $j i k i$ (不祝儀敷き) (7b). In fact, in residential architecture, tatami are laid in an interlocking or spiral fashion, so that the strips of fabric along their long edges do not form continuous lines, like in Hyuga Villa. Katsura Villa features rooms with fushügi layout too, where the drop ceiling has rafters running at a 90-degree angle with the tatami lines. Taut-with the aid of Japanese staff-followed this principle, when designing the Japanese livingroom. As this space faces both South and West, sun shading was a major preoccupation for the architect. Taut dreaded especially Japan's evening Western sunlight: (Taut 2011, 180) therefore he conceived a West-oriented terrace fitted with top-hinged wooden sunbreakers with movable louvers (8a). The way they fold vertically is reminiscent of shitomido, a centuries-old feature of temples and upperclass architecture, used not only for shading, but for privacy and security as well (8b). Taut here arguably introduced for the first time in Japan movable louvers, to better modulate light while allowing airflow. In fact, he believed his invention would spread through the country and become a popular architectural feature (Figure 6).

Hyuga Villa was completed in September 1936 and would be first presented outside Japan in the French 
architectural journal L'Architecture d'Aujourd'hui in January 1937, with a text titled 'Une habitation Japonaise', written by the architect himself, and accompanied by plans and photographs. Just after the publication of Japans Kunst mit europäischen Augen gesehen (Japanese art seen with European eyes), on October 15, 1936, Taut and Erica left Japan. They travelled through Korea, China (Puppet Manchukuo) and Russia, before arriving in Turkey.

After spending two and a half years in the Far East, Taut settled in Istanbul, at the crossroad of Eastern and Western cultures. During his stay in Turkey, Taut served as both dean and rector of the Istanbul Academy of Arts while receiving commissions to design schools (among others the Faculty of Philology of the University of Ankara), having become the director of the Buildings Division at the Ministry of Education. Burdened with an excessive amount of work, he completed in November 1938 his last commission, the design of the catafalque for the death of Mustafa Kemal Atatürk, before dying on the following Christmas Eve.

\section{Discussion}

The examination of Hyuga Villa in relation to the question of 'translation' offers the opportunity to concentrate on two major themes, which maintain their relevance in present days: the idea of appropriateness in architecture, which Taut named Proportion, and the relationship between East and West. During his stay in Istanbul, Taut finalised a compendium of architecture lessons-the $\mathrm{Ar}$ chitekturlehre (mimarî bilgisi in Turkish) - where he examined selected buildings around the world and advanced his ideas about the essence and role of the architectural profession. In one of the book's paragraphs he explicitly defines architecture as the art of proportions. According to him, the term 'architecture' is to be conceived as the skill to bring all aspects of a project into harmony, so that materials, construction, and function achieve a sense of appropriateness that resonates with the site and context, most importantly with local climate. Appropriateness-a possible translation of the German word Proportion used by Taut-is not only related to form, but includes, beside measurable and objective specifications, more subjective aspects, from the point of view of both the designer and the user. In fact, the view on the Pacific Ocean and the hot and humid climate of Atami were relevant aspects determining Taut's design, something that enables to draw parallels with the contemporary debate about sustainability, contested between quantitative and qualitative standpoints. The careful choice of materials, their detailing and positioning testify of a desire to reach the appropriate Stimmung through a haptic spatial experience, stimulating bodily perceptions that transcend the visual realm. From this point of view, Taut's architectural approach, starting from concrete and local concerns, could be defined as 'Aristotelian', in contrast to the 'Corbusian', platonic form, aspiring to an idealised model.

The second major theme addressed by Taut in this project is cross-cultural breeding. Hyuga Villa's design, being a hybrid between Japanese and European aesthetics and sensibilities, is also emblematic with regard to Taut's own experience as a foreigner operating in a different culture, and, in a broader sense, to the relationship between East and West. As Taut himself wrote, 'Every country is East and has its East. ... A Japanese can only come to a spiritual Europe from a spiritual Japan-as a European can only come to a spiritual Japan from a spiritual Europe. And both will enrich themselves along this journey. ... As a European I have written' (Taut 2011, 191, 193, 195-196). While translating from the local traditional architectural vocabulary, the architect achieved a wide range of results: for instance, he quoted Katsura Villa's ranma or tatami layout literally and almost without alteration; he employed materials in a novel manner in terms of construction and placement, such as bamboo being used as an indoor wall covering; he took conceptual inspiration from local culture to produce utterly unique design solutions, as seen with the wavy lighting in the ping-pong room-akin to the Japanese principle of layered allusion called mitate (見 立 ). Translation here does not appear as a process that loses something of the original along the way, but rather produces novelty, even though marked by a personal, partial and selective understanding of the source. This seems only natural, though, as architecture, like 'the work of art, while outwardly the product or illustration of a cultural situation, is in the final analysis the creation of an individual. Where East and West meet is in the mind of the artist himself, and the processes of acceptance and transformation depend ultimately on the choices that he makes.' (Sullivan 1989, 274)

To Taut's disappointment, the project for Hyuga Villa failed to attract the attention he believed it deserved. Locals found the building simply odd, and were especially struck by the bold use of colors in the interior spaces. European architects, inclined to the puristic volumes of classic Modernism, seem to have shunned the building (The Formwork 2016). It is worth noting here, that, at the time, only black and white photographs were available. It has been argued, by Beatriz Colomina and Kengo 
Kuma among others, that the preference for white, sculptural forms of modern architects like Le Corbusier was a reaction to the expressive potentials of black and white photography for publicity and self-promotion (Colomina 1994; Kuma 2007, 12-15). The work of Taut, in this respect, relying on colors and materiality, was ill-suited to this medium. Taut himself noted in his diary that the villa had not been built to be photographed, and that its proportions, details, materials and colors could not be conveyed by means of a picture (Speidel 2006, 45).

Hyuga Villa, sold to a private company to be used as a seaside retreat for management cadres, was purchased by the municipality of Atami in 2004, thanks to the financial contribution of a private local patron. Subsequently, it underwent a conservative renovation that nonetheless altered to a certain degree materials and detailing. The original lighting concept and effect was lost due to the use of additional lamps, and an array of devices on the walls and ceiling were introduced for safety purposes. Specifically, the wavy light bulbs in the ping-pong room-too peculiar in construction to meet current regulations-cannot be switched on anymore. In this respect, it seems to persist an 'either/or' scenario: either conserving material integrity at the expense of the intended lighting concept, or installing new and functioning lamps at the expense of physical substance. Some of the original furniture has disappeared and it is questionable whether the colors of the newly plastered walls are true to the original. Moreover, new balustrades and supplementary external windows considerably alter the view toward the outside. From this point of view, Hyuga Villa faces a conservation dilemma, concerning the integrity and originality of materials, that is, its physical authenticity. In fact, the fragility of the employed materials and the uniqueness of their detailing call for replacement after decades of service, to some extent ruling out strict preservation. While the standard value-centered Japanese attitude toward built heritage conservation works well with wooden structures-it should suffice to mention the continuous demolition and rebuilding of Ise Grand Shrine every twenty years-it does not wholly fit Hyuga Villa.

In 2006 the Taut-designed basement was designated as an Important Cultural Property (jūyō bunkazai一 重要文 化財). Day-to-day maintenance is currently provided by a group of volunteers, who are enthusiastic about their work but who tend to lack the resources and technical skills required for the proper conservation of such a fragile structure. Nonetheless, these volunteers are able to open Hyuga Villa on weekends and to offer guided tours. This is a case of machizukuri (literally, town-making), a typical Japanese bottom-up participatory practice, one that highlights the increasingly relevant role of civic involvement in heritage conservation (González Martínez 2017).

At the point of writing, Hyuga Villa is scheduled to undergo a second extensive restoration. Renovation works are expected to last three years-starting from Spring 2018-with a budget of 320 million yen (approximately three million US dollars) provided by the City of Atami, the Shizuoka Prefecture, and the national Agency for Cultural Affairs (bunka chō- 文化庁). It does remain to be seen whether a balance can be struck between Eastern and Western conservation practices: while we are looking forward to evaluating the outcomes of the upcoming renovation, the selected material from our complete architectural and photographic survey presented in these pages might help reassess Hyuga Villa's cultural and historical relevance as a unique piece of built heritage ${ }^{7}$.

\section{Notes}

1. This and the following five sections, including the Preliminary Conclusions, have been written by Paolo Scrivano.

2. Some of these questions are addressed by Esra Akcan in her Architecture in Translation: Germany, Turkey, and the Modern House (2012): however, a thorough discussion of this volume-dedicated to Turkish modernism in its relation to German architectural culture and often mentioned in relation to translation because of its captivating title-is not the aim of the present text.

3. On the history of Vers une architecture see: Cohen 2007.

4. As Diane Ghirardo, one of the two translators, later declared, in the preface Eisenman reinterpreted Rossi's ideas reformulating them as 'a projection of his owns': Ghirardo 1998.

5. This and the following sections have been written by Marco Capitanio.

6. The facade adaptation of House Okura in TokyoTaut's other Japanese project-was lost with the demolition of the building.

7. These materials were on display in exhibition format at different venues between 2016 and 2018, under the title 'West of Japan/East of Europe. Bruno Taut's Hyuga Villa.'

\section{Acknowledgement}

On October 18, 2017, the Department of Architecture at Xian Jiaotong-Liverpool University, in Suzhou, hosted the 
international symposium 'West of Japan/East of Europe', in concomitance with the opening of the exhibition 'Bruno Taut's Hyuga Villa in Atami, Japan'. Curated by Marco Capitanio and with photographs by Dave Clough, the show had been previously displayed in Venice and Tokyo and later traveled to Milan and Stockholm. The text published above is based on two communications presented at the event. The authors want to express their gratitude to Professor Pierre-Alain Croset, past Head of the Department of Architecture at Xi'an Jiaotong-Liverpool University, for his support to the initiative.

\section{References}

Bédarida, Marc. 1987. "Rue de Sèvres, 35. L’envers du décor." In Le Corbusier, une enciclopédie, 354-359. Paris: Centre Pompidou.

Bourdieu, Pierre. 1979. La Distinction. Critique sociale du jugement. Paris: Éditions de Minuit.

Bourdieu, Pierre. 2002. "Les conditions sociales de la circulation internationale des idées." Actes de la recherche en sciences sociales, 145: 3-8.

Canclini, Néstor García. 1990. Culturas híbridas. Estrategias para entrar y salir de la modernidad. México D. F.: Grijabo - Consejo Nacional para la Cultura y las Artes.

Ceccarelli, Paolo. 2017. "Past is not a Frozen Concept: Considerations about Heritage Conservation in a Fast Changing World." Built Heritage 1 (3): 1-12.

Cohen, Jean-Louis. 2007. “Introduction.” In Le Corbusier. Toward an Architecture, 1-78. Los Angeles: The Getty Research Institute.

Colomina, Beatriz. 1994. Privacy and Publicity: Modern Architecture as Mass Media. Cambridge, Mass.: MIT Press.

Chatterjee, Malay. 1985. “1960-1974: De retour de Chandigarh”. In Architectures en Inde, 132-135. Milan-Paris: Electa Moniteur.

De Andrade, Oswald. 2000. A utopia antropofágica. São Paulo: Globo.

Fairbank, Wilma. 1994. Liang and Lin: Partners in Exploring China's Architectural Past. Philadelphia: University of Pennsylvania Press.

Fraser, Valerie. 2000. Building the New World: Studies in the Modern Architecture of Latin America 1930-1960. London-New York: Verso.

Ghirardo, Diane. 1998. "Aldo Rossi en los Estados Unidos." Block: Revista de cultura de la arquitectura, la ciudad y el territorio 3: 102-109.

González Martínez, Plácido. 2017. “Built Heritage Conservation and Contemporary Urban Development: The
Contribution of Architectural Practice to the Challenges of Modernisation." Built Heritage 1 (1): 14-25.

Kuma, Kengo. 2007. Anti-Object? The Dissolution and Disintegration of Architecture. London: AA Publications.

Morse, Edward S. 1886. Japanese Homes and Their Surroundings. Boston: Ticknor and Company.

Pellnitz, Alexander. 2014. "Rossi e la Germania. Traduzione e ricezione del libro 'LAArchitettura della Città.' In Aldo Rossi, la storia di un libro. L'architettura della città, dal 1966 ad oggi, edited by Fernanda De Maio, Alberto Ferlenga, and Patrizia Montini Zimolo, 212-221. Venice: Università Iuav di Venezia - Il Poligrafo.

Rossi, Aldo. 1966. L’Architettura della Città. Venice: Marsilio.

Shaw, Lauren. 2014. “Migrants as 'Translators': Mediating External Influences on Post-World II Western Europe, 1945-1973." Bulletin of the German Historical Institute 54: $125-130$.

Speidel, Manfred, ed. 1994. Bruno Taut Retrospective. Nature and Fantasy. Tokyo: Treville.

Speidel, Manfred. 2006. "Il magnifico esilio giapponese." Casabella 743: 45-51.

Sullivan, Michael. 1989. The Meeting of Eastern and Western Art. Berkeley-Los Angeles, Cal.: University of California Press.

Taut, Bruno. 1936. Fundamentals of Japanese Architecture. Tokyo: Kokusai Bunka Shinkokai.

Taut, Bruno. 1937. Houses and People of Japan. Tokyo: Sanseido.

Taut, Bruno. 2003. Ich liebe die japanische Kultur: Kleine Schriften über Japan. Berlin: Mann.

Taut, Bruno. 2009. Nippon mit europäischen Augen gesehen. Berlin: Mann.

Taut, Bruno. 2011. Japans Kunst mit europäischen Augen gesehen. Berlin: Mann.

The Formwork. 2016. "Kengo Kuma on Bruno Taut and Hyuga Villa in Atami - Interview." Tokyo: Gaienmae. Accessed 5 January 2018. https://www.youtube.com/ watch? $\mathrm{v}=\mathrm{NyDNnx} 1 \mathrm{M} 8 \mathrm{~T} 0$ 